University of Nebraska - Lincoln

DigitalCommons@University of Nebraska - Lincoln

Faculty Publications, Department of Psychology

Psychology, Department of

2004

Cognitive constraints on reciprocity and tolerated scrounging

Jeffrey R. Stevens

University of Nebraska-Lincoln, jstevens5@unl.edu

Fiery A. Cushman

Harvard University, cushman@wjh.harvard.edu

Follow this and additional works at: https://digitalcommons.unl.edu/psychfacpub

Part of the Psychiatry and Psychology Commons

Stevens, Jeffrey R. and Cushman, Fiery A., "Cognitive constraints on reciprocity and tolerated scrounging" (2004). Faculty Publications, Department of Psychology. 529.

https://digitalcommons.unl.edu/psychfacpub/529

This Article is brought to you for free and open access by the Psychology, Department of at DigitalCommons@University of Nebraska - Lincoln. It has been accepted for inclusion in Faculty Publications, Department of Psychology by an authorized administrator of DigitalCommons@University of Nebraska - Lincoln. 


\section{Cognitive constraints on reciprocity and tolerated scrounging}

\author{
Jeffrey R. Stevens and Fiery A. Cushman \\ Department of Psychology, Harvard University, Cambridge, MA 02138. \\ jstevens@wjh.harvard.edu cushman@wjh.harvard.edu \\ http://wjh.harvard.edu/ jstevens
}

\begin{abstract}
Each of the food-sharing models that Gurven considers demands unique cognitive capacities. Reciprocal altruism, in particular, requires a suite of complex abilities not required by alternatives such as tolerated scrounging. Integrating cognitive constraints with comparative data from other species can illuminate the adaptive benefits of food sharing in humans.
\end{abstract}

Gurven argues that reciprocal altruism (RA) provides the best adaptive account of human food sharing, explaining the patterns better than tolerated scrounging (TS), kin selection, and costly signaling. We contend that the emphasis on RA may be overstated, whereas the analysis of TS is overly critical. To address the overemphasis on RA, we make the following argument: First, a more recent model of TS situations avoids the specific assumptions and predictions of previous models, providing a more generally applicable version of TS. Second, the presence of contingency is not sufficient to invoke RA, because confounding factors can produce reciprocal patterns. Third, using a comparative ap- proach, we argue that RA rarely occurs in nonhuman animals, probably because of the complex cognitive skills required to reciprocate. Given these cognitive constraints, we examine the adaptive history of human food sharing originating from TS situations. In total, these contentions suggest that, minimally, TS provides as reasonable an explanation of the available data on human food sharing as RA does.

Gurven adopts a strict definition of TS. Although the previous optimality models of TS considered by Gurven require special circumstances and make overly specific predictions (Blurton Jones 1984; Winterhalder 1996a), a recent model of TS based on more general assumptions does not predict egalitarian food sharing (Stevens \& Stephens 2002). This model predicts that if the beggar's harassment is costly enough to the owner, the owner may relinquish a fraction of the food to the beggar to avoid these costs. The optimal amount shared depends on the costs of harassment to the owner and to the beggar, as well as the consumption rate of the consumers, so equal distribution of the food is unlikely. In contrast to the original TS formulation, in the Stevens and Stephens model the food owners can control the distribution of the food and the marginal value does not have to decrease. Therefore, many of Gurven's assumptions and predictions for the TS model do not apply to the more general harassment model.

In contrast to his strict view of TS, Gurven uses very relaxed criteria for RA. His crucial evidence for RA is the contingency of giving - individual A's sharing with B correlates with B's sharing with A. This type of analysis is necessary but not sufficient to assess contingency because of potential confounding factors such as association. Rather than being contingent on previous instances, sharing may result from associational relationships between individuals (de Waal \& Luttrell 1988); that is, individuals who interact frequently for any reason, tend to demonstrate reciprocal sharing patterns. Moreover, repeated, reciprocal TS interactions could lead to patterns of sharing identical to RA. Therefore, examining long-term patterns of contingency alone cannot provide the resolution to distinguish between RA and repeated TS interactions. Gurven is clearly aware of these issues, but much of the available data does not allow him to test between these alternative hypotheses.

The distinction between RA and TS is further complicated by Gurven's inclusion of punishment with RA. Theoretical investigations of reciprocal altruism suggest that punishment and social norms may play a critical role in maintaining cooperative behavior (Boyd et al. 2003; Gintis 2000). And indeed, Gurven's survey of the literature reveals that punishment and coercion regularly occur in hunter-gatherer societies. As Gurven himself points out, however, "the resulting 'reciprocal' TS . . . is essentially identical to RA” (sect. 8.3, para. 1). In light of this convergence, how do we distinguish between the two hypotheses?

Because the present view of human food sharing - one enforced by social norms and punishment - is equally compatible with TS and RA models, we examine the probability that each model accounts for the adaptive history of food sharing. Comparative data suggest that the cognitive constraints on RA pose a substantial barrier to its evolution (Stevens \& Hauser 2004), whereas the considerably more relaxed constraints on TS make it a likely candidate to explain present behaviors. In addition, empirical support for RA is virtually nonexistent in nonhuman animals (Hammerstein 2003). Even in the few cases that report RA, such as vampire bats (Wilkinson 1984) and primates (Brosnan \& de Waal 2002), it either is rare or requires special conditions (Hauser et al. 2003; Stephens et al. 2002). Evidence for TS and harassment, however, is much more common among animals (Clutton-Brock \& Parker 1995; Stevens \& Gilby 2004).

Why might reciprocity rarely occur and harassment commonly occur in animals? An important difference between RA and TS is the timescale over which the costs and benefits accrue. RA implies that an individual pays an immediate cost to share and waits a period of time before recouping that cost, presenting at least two barriers to cooperation. First, animals (including humans) prefer immediate over future benefits, and, therefore, devalue future re- 
Commentary/Gurven: To give and to give not: The behavioral ecology of human food transfers

wards. As Gurven points out, discounting has important consequences in cooperative interactions (Rachlin 2002). Individuals who highly discount future rewards may have difficulty employing reciprocal sharing strategies. Second, introducing a time delay requires that individuals remember that they owe a debt or have given a favor to another, and remember the amount of that debt or favor. Memory decay and interference can make tracking debts and favors difficult. The presence of a time delay allows for interactions with multiple individuals, further increasing the cognitive load by requiring simultaneous tracking of interactions with several partners. For these reasons, the probability of sharing should be inversely related to the expected reciprocation time.

TS strategies do not suffer from the same limitations because the benefit to the harasser accrues immediately. Whereas RA demands the evolution of a cognitively taxing strategy, harassment demands the evolution of a relatively simpler strategy in which selfish instincts result in immediate rewards. Implementing repeated TS strategies not only superficially resembles RA, but may pave the way for RA by introducing a behavioral repertoire of enforced social norms on which stable RA strategies ultimately depend (Blurton Jones 1984).

The argument from cognitive constraints is not designed to be a knock-down punch, nor do we expect that any single model will stand alone in the final rounds. Like Gurven, we suspect that elements of each of these models may be at play in the context of human food sharing. It would be a mistake, however, to broadly construe the predictions of RA while narrowly confining the predictions of alternative hypotheses to a restricted set. Existing evidence of food sharing is equally compatible with the harassment model of TS, and the lower cognitive demands of harassment favor it as an adaptive hypothesis.

ACKNOWLEDGMENTS

We would like to thank Marc Hauser for comments and the National Institutes of Health for funding for JRS. 